\title{
Biotechnological Approaches to Improve Carbon Fixation in Agricultural Crops
}

ISSN: 2637-7659

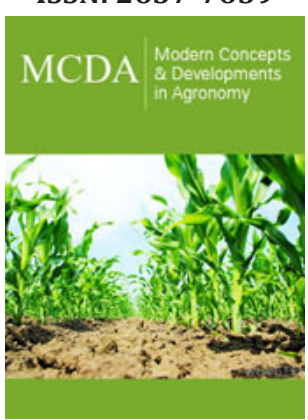

*Corresponding author: Luis F García del Moral, Department of Plant Physiology, Faculty of Sciences, University of Granada, Spain

Submission: 啙 August 05, 2020

Published: 眥September 16, 2020

Volume 7 - Issue 3

How to cite this article: Garcia del Moral LF, Boujenna A. Biotechnological Approaches to Improve Carbon Fixation in Agricultural Crops. Mod Concep Dev Agrono. 7(3). MCDA. 000661. 2020. DOI: 10.31031/MCDA.2020.07.000661

Copyright@ Garcia del Moral LF, This article is distributed under the terms of the Creative Commons Attribution 4.0 International License, which permits unrestricted use and redistribution provided that the original author and source are credited.

\author{
Garcia del Moral LF ${ }^{1 *}$ and Boujenna $\mathrm{A}^{2}$
}

${ }^{1}$ Department of Plant Physiology, Faculty of Sciences, University of Granada, Spain

${ }^{2}$ Département de Biologie Végétale, Faculté des Sciences, Université Abdel Malek Essadi, Tetouan, Morocco

\begin{abstract}
Photosynthesis is the basis of the primary production. Conventional breeding has produced notable increases in crop productivity, although a substantial improvement in photosynthesis per se has not yet been achieved. This mini review summarizes the possibilities for biotechnological manipulation of photosynthesis and their possible application for crop improvement.
\end{abstract}

Keywords: Photosynthesis; Rubisco; Photorespiration; Stomatal conductance; Carboxysomes; Pyrenoids Abbreviations: RUBISCO: Ribulose-1,5-Bisphosphate Carboxylase Oxygenase; NPQ: Nonphotochemical Quenching; PhAR: Photosynthetic Active Radiation

\section{Introduction}

Currently, the knowledge of the biochemical and molecular basis on which the complex processes of $\mathrm{CO}_{2}$ acquisition by plants are based may allow attempts to improve it by genetic modification. Since photosynthesis is the basis of plant growth and productivity, improving its efficiency may contribute to greater food security in the coming decades as the world population increases. Multiple targets have been identified that could be improved through biotechnology to increase photosynthesis of crops [1-6].

\section{Engineering photosynthetic enzyme activity}

Under intense light conditions, photosynthesis is limited by the $\mathrm{CO}_{2}$ supply, by the working capacity of Rubisco and by the regeneration rate of ribulose 1,5-bisphosphate (the five-carbon substrate for Rubisco). Potential possibilities are to increase the amount of Rubisco molecules and to improve their affinity for the $\mathrm{CO}_{2}$ to increase their carboxylase capacity and decrease oxygenase activity (photorespiration) $[3,7,8]$. However, the problem arises since carboxylase activity is not only a function of the number of Rubisco molecules, but is modulated by the concentrations of its cofactors (mainly supply of $\mathrm{CO}_{2}$ and $\mathrm{Mg}_{2}^{+}$) and by the regeneration rate of ribulose 1,5-bisphosphate, in addition to other enzymes of the Calvin cycle [3,7,9]. However, by overexpressing the small and large subunits of the Rubisco, together with an assembly chaperone protein, it was possible to increase photosynthesis and biomass in corn [10]. In tobacco, enzymes involved in glycolate metabolism have been inserted into chloroplasts to reduce photorespiration, along with reduced expression of a glycolate and glycerate transporter to minimize the flow of glycolate out of the chloroplast, increasing thus vegetative biomass in a $40 \%$ under field conditions [11]. Other actions at the enzymatic level have involved an increase in the activity of sedoheptulose 1,7-bisphosphatase, one of the key enzymes in the regulation of the Calvin-Benson cycle [12]. Thus, in transgenic wheat, the overexpression of this enzyme caused an increase in photosynthesis and grain yield [13]. It has also been suggested that the tolerance of photosynthesis at higher temperatures could be increased by improving the thermal stability of Rubisco activase, the enzyme that induces its activity under lighting conditions [14]. 


\section{Introducing the $\mathrm{C}_{4}$ cycle in $\mathrm{C}_{3}$ crops}

The possibility of introducing $\mathrm{C}_{4}$ photosynthetic metabolism in $\mathrm{C}_{3}$ crops such as wheat or rice, is one of the most important challenges in engineering photosynthesis [15-17]. At present, transgenic $\mathrm{C}_{3}$ plants have been obtained that express at least one set of key enzymes of the photosynthetic $\mathrm{C}_{4}$ pathway. However, those $C_{3}$ transgenic plants that overproduce a single $C_{4}$ enzyme show alterations in carbon metabolism [15-17]. Therefore, the correct post-translational regulation of the introduced heterologous enzymes, the adjustment of the levels of auxiliary enzymes (such as carbonic anhydrase, adenylate kinase and pyrophosphatase) and the metabolite transporters must also be addressed, as well as to achieve an effective mechanism of $\mathrm{CO}_{2}$ concentration in the chloroplast stroma [15-17]. Alternatively, work is currently underway on the engineering of cyanobacterial carboxysomes or pyrenoid algae in $\mathrm{C}_{3}$ plants. Carboxysomes are bacterial polyhedral micro-compartments consisting of protein layers containing Rubisco and a carbonic anhydrase, so that they act by concentrating $\mathrm{CO}_{2}$, thus improving photosynthesis efficiency, while reducing photorespiration. Currently, it has been possible to partially assemble carboxysomes of cyanobacteria in tobacco, as well as to express genes for the enzyme Rubisco specific for cyanobacteria [18-20]. The introduction of the BicA and SbtA membrane transporters with a high affinity for bicarbonate ion of cyanobacteria in the envelope of the chloroplast has also been proposed as a mechanism for $\mathrm{CO}_{2}$ concentration [21]. Another strategy, although less developed, is to introduce algae pyrenoids, subcellular organelles located in the plastid stroma of almost all eukaryotic microalgae with large amounts of Rubisco together with a high activity of carbonic anhydrase [22,23].

\section{Engineering components of the photochemical system}

Under excessive radiation and to avoid photooxidation of chlorophylls and subsequent damage to Photosystems, green leaves have several mechanisms that allow to dissipate excess energy that cannot be used for photosynthesis. One of these mechanisms is the so-called nonphotochemical quenching (NPQ) that protects chlorophylls from damage by heat emission, but in this process, energy is lost that is not used for photosynthesis and biomass production [24-26]. In the case of the NPQ its activation is quite fast, but not its return to the basal level, so a faster thermal relaxation of the NPQ after a decrease in the light level, could increase the energy available for photosynthesis in instead of continuing to dissipate it in the form of heat, especially under conditions of fluctuating light, as they usually occur inside the leaf canopy. In fact, some theoretical studies of the kinetics of the process indicate that the loss in $\mathrm{CO}_{2}$ fixation due to the slow deactivation of NPQ could be as high as $30 \%$ [27].Recently, it has been possible to accelerate the return of NPQ to its basal level in tobacco by introducing genes from Arabidopsis thaliana for three proteins (PsbS, VDE and ZEP) involved in the xanthophyll cycle, thus increasing biomass production by up to $20 \%$ in greenhouse trials and around $15 \%$ in field trials [28]. Another strategy is to extend the spectrum of photosynthetic active light absorption (PhAR), which is located in the band between 400 and $700 \mathrm{~nm}$ wavelengths and represents approximately $50 \%$ of the energy of sunlight [29]. Few photons with wavelengths greater than $700 \mathrm{~nm}$ are absorbed by the leaves, as they are almost entirely reflected or transmitted by leaves. However, chlorophylls $d$ and $f$ from cyanobacteria are capable of capturing light up to $750 \mathrm{~nm}$, so they could be used to extend photochemistry in terrestrial plants, thus increasing photons available for photosynthesis in sunlight by up to $19 \%[30]$.

\section{Increased $\mathrm{CO}_{2}$ uptake}

To increase the uptake of $\mathrm{CO}_{2}$ in $\mathrm{C}_{3}$ plants, the classic approach has been to increase stomatal conductance [31], but this also drastically increases the rate of transpiration, since under most circumstances the outflow of water is much greater than the flow of $\mathrm{CO}_{2}$ input [3]. Consequently, increased stomatal conductance would be detrimental to productivity in dry environments, although it has been found to correlate with higher yields under good irrigation conditions [32]. Another alternative is to modify the conductance of the mesophyll to $\mathrm{CO}_{2}$, which depends on two anatomical attributes of the leaf, the surface of the mesophyll cells exposed to the intercellular airspaces and the thickness of their cell walls, factors that are currently difficult to modify by Genetic Engineering $[33,34]$. Furthermore, the permeability to $\mathrm{CO}_{2}$ of the plasmalema and the chloroplast membranes must be also considered.

In this sense, it has been pointed out that certain aquaporins could also function as channels for $\mathrm{CO}_{2}$ because although lipid bilayers are highly permeable to $\mathrm{CO}_{2}$, biological membranes are very rich in proteins, which greatly reduce the area available for the diffusion of $\mathrm{CO}_{2}$ through lipids [35,36]. In fact, the overexpression of some aquaporins such as HvPIP2; 1 in rice [37], NtAQP1 in tobacco [38] and PIP1;2 in Arabidopsis thaliana [39] was associated with an increase in the conductance of mesophyll to $\mathrm{CO}_{2}$. However, the physiological interpretation of these results is not straightforward, due to associated pleiotropic changes and technical challenges since, unfortunately, measuring the permeability of the membrane to $\mathrm{CO}_{2}$ is difficult. For example, in rice, overexpression of HvPIP2;1 was accompanied by an increase in the thickness of the mesophyll cell walls [37]. However, the modification of certain aquaporins is a very interesting strategy to facilitate the diffusion of $\mathrm{CO}_{2}$ through the plasma membrane and the envelope of the chloroplast and to collaborate in the possibility of introducing the $\mathrm{C}_{4}$ photosynthetic pathway in $\mathrm{C}_{3}$ agricultural crops.

\section{Conclusion}

While modern crops are highly efficient at rapidly unfolding their leaves to maximize light interception, they are not as efficient at converting absorbed light energy to carbohydrates through photosynthesis. This may be due to the fact that the proteins and enzymes implicated in the photosynthetic process evolved in a marine environment with little light and absence of oxygen, very different therefore from current agronomic and atmospheric conditions. However, as we have discussed, there are several biotechnological possibilities, although the modification of photosynthesis at the chloroplast or leaf level should be accompanied by an improvement at the level of the crop canopy. 


\section{Acknowledgement}

Work funded by Junta de Andalucia Grupo AGR123.

\section{References}

1. Mittler R, Blumwald E (2005) Genetic engineering for modern agriculture: Challenges and perspectives. Annu Rev Plant Biol 61: 443462.

2. Ainsworth EA, Rogers A, Leakey AD (2008) Targets for crop biotechnology in a future high- $\mathrm{CO}_{2}$ and high- $\mathrm{O}_{3}$ world. Plant Physiol 147(1): 13-19.

3. Evans JR (2013) Improving photosynthesis. Plant Physiol 162: 17801793.

4. Dann M, Leister D (2017) Enhancing (crop) plant photosynthesis by introducing novel genetic diversity. Phil Trans R Soc B 372(1730): 20160380.

5. Bailey Serres J, Parker JE, Ainsworth EA, Oldroyd GED, Schroeder JI (2019) Genetic strategies for improving crop yields. Nature 575(7781): 109-118.

6. Furbank RT, Sharwood R, Estavillo GM, Silva Perez V, Condon AG (2020) Photons to food: genetic improvement of cereal crop photosynthesis. J Exp Botany 71(7): 2226-2238.

7. Parry MAJ, Andralojc PJ, Scales JC, Salvucci ME, Carmo Silva AE, et al. (2013) Rubisco activity and regulation as targets for crop improvement. J Exp Bot 64(3): 717-730.

8. Prins A, Orr DJ, Andralojc PJ, Reynolds MP, Carmo Silva E, et al. (2016) Rubisco catalytic properties of wild and domesticated relatives provide scope for improving wheat photosynthesis. J Exp Botany 67(6): 18271838.

9. Simkin AJ, López Calcagno PE, Raines CA (2019) Feeding the world: improving photosynthetic efficiency for sustainable crop production. J Exp Botany 70(4): 1119-1140.

10. Salesse Smith CE, Sharwood RE, Busch FA, Kromdijk J, Bardal V, et al. (2018) Overexpression of Rubisco subunits with RAF1 increases Rubisco content in maize. Nat Plants 4(10): 802-810.

11. South PF, Cavanagh AP, Liu HW, Ort DR (2019) Synthetic glycolate metabolism pathways stimulate crop growth and productivity in the field. Science363(6422): eaat9077.

12. Lefebvre S, Lawson T, Zakhleniuk OV, Lloyd JC, Raines CA, et al. (2005) Increased sedoheptulose-1,7-bisphosphatase activity in transgenic tobacco plants stimulates photosynthesis and growth from an early stage in development. Plant Physiol 138(1): 451-460.

13. Driever SM, Simkin AJ, Alotaibi S, Fisk SJ, Madgwick PJ, et al. (2017) Increased SBPase activity improves photosynthesis and grain yield in wheat grown in greenhouse conditions. Philos Trans R Soc Lond B Biol Sci 372(1730): 20160384.

14. Carmo Silva AE, Salvucci ME (2013) The regulatory properties of Rubisco activase differ among species and affect photosynthetic induction during light transitions. Plant Physiol 161(4): 1645-1655.

15. Matsuoka M, Furbank RT, Fukayama H, Miyao M (2001) Molecular engineeringof $\mathrm{C}_{4}$ photosynthesis. Annu Rev Plant Physiol Plant Mol Biol 52: $297-314$

16. Sharwood RE, Ghannoum O, Whitney SM (2016) Prospects for improving $\mathrm{CO}_{2}$ fixation in $\mathrm{C}_{3}$-crops through understanding $\mathrm{C}_{4}$-Rubisco biogenesis and catalytic diversity. Curr Opin Plant Biol 31: 135-142.

17. Wang P, Vlad D, Langdale J (2016) Finding the genes to build $\mathrm{C}_{4}$ rice. Curr Opin Plant Biol 31: 44-50.

18. Hanson MR, Lin MT, Carmo Silva AE, Parry MAJ (2016) Towards engineering carboxysomes into $\mathrm{C}_{3}$ plants. Plant J 87(1): 38-50.
19. Long BM, Rae BD, Rolland V, Förster B, Price GD (2016) Cyanobacterial $\mathrm{CO}_{2}$-concentrating mechanism components: function and prospects for plant metabolic engineering. Curr Opin Plant Biol 31: 1-8.

20. Price GD, Pengelly JJL, Forster B, Du J, Whitney SM, et al. (2013) The cyanobacterial CCM as a source of genes for improving photosynthetic $\mathrm{CO}_{2}$ fixation in crop species. J Exp Bot 64(3): 753-768.

21. Rolland V, Badger MR, Price GD (2016) Redirecting the cyanobacterial bicarbonate transporters BicA and SbtA to the chloroplast envelope: Soluble and membrane cargos need different chloroplast targeting signals in plants. Front Plant Sci 7: 185.

22. Meyer MT, McCormick AJ, Griffiths $\mathrm{H}$ (2016) Will an algal $\mathrm{CO}_{2}$ concentratingmechanism work in higher plants? Curr Opin Plant Biol 31: 181-188.

23. Rae BD, Long BM, Förster B, Nguyen ND, Velanis CN, et al. (2017) Progress and challenges of engineering a biophysical $\mathrm{CO}_{2}$-concentrating mechanism into higher plants. J Exp Bot 68(14): 3717-3737.

24. Murchie EH, Niyogi KK (2011) Manipulation of photoprotection to improve plant photosynthesis. Plant Physiol 155: 86-92.

25. Horton RM, Mankin JS, Lesk C, Coffel E, Raymond C (2016) A review of recent advances in research on extreme heat events. Curr Cli Change Rep 2: 242-259.

26. Schreiber U, Klughammer C, Schansker G (2019) Rapidly reversible chlorophyll fluorescence quenching induced by pulses of supersaturating light in vivo. Photosynth Res 142(1): 35-50.

27.Zhu XG, Ort DR, Whitmarsh J, Long SP (2004) The slow reversibility of photosystem II thermal energy dissipation on transfer from high to low light may cause large losses in carbon gain by crop canopies: a theoretical analysis. J Exp Bot 55(400): 1167-1175.

28. Kromdijk J, Głowacka K, Leonelli L, Gabilly ST, Iwai M, et al. (2016) Improving photosynthesis and crop productivity by accelerating recovery from photoprotection. Science 354(6314): 857-861.

29. Chen M, Blankenship RE (2011) Expanding the solar spectrum used by photosynthesis. Trends Plant Sci 16(8): 427-431.

30. Chen M, Schliep M, Willows RD, Cai ZL, Neilan BA, et al. (2010) Aredshifted chlorophyll. Science 329(5997): 1318-1319.

31. Rebetzke GJ, Rattey AR, Farquhar GD, Richards RA, Condon AG (2012) Genomic regions for canopy temperature and their genetic association with stomatal conductance and grain yield in wheat. Funct Plant Biol 40(1): 14-33.

32. Fischer RA, Rees D, Sayre KD, Lu ZM, Condon AG, et al. (1998) Wheat yield progress associated with higher stomatal conductance and photosynthetic rate, and cooler canopies. Crop Sci 38(6): 1467-1475.

33. Evans JR, von Caemmerer S, Setchell BA, Hudson GS (1994) The relationship between $\mathrm{CO}_{2}$ transfer conductance and leaf anatomy in transgenic tobacco with a reduced content of Rubisco. Aust J Plant Physiol 21(4): 475-495.

34. Tholen D, Zhu XG (2011) The mechanistic basis of internal conductance: atheoretical analysis of mesophyll cell photosynthesis and $\mathrm{CO}_{2}$ diffusion. Plant Physiol 156(1): 90-105.

35. Groszmann M, Osborn HL, Evans JR (2017) Carbon dioxide and water transport through plant aquaporins. Plant Cell Env 40(6): 938-961.

36. Flexas J, Niinemets U, Galle A, Barbour MM, Centritto M, et al. (2013) Diffusional conductances to $\mathrm{CO}_{2}$ as a target for increasing photosynthesis and photosynthetic water-use efficiency. Photosynth Res117(1-3): 4559.

37. Hanba YT, Shibasaka M, Hayashi Y, Hayakawa T, Kasamo K, et al. (2004) Overexpression of the barley aquaporin HvPIP2;1 increases internal $\mathrm{CO}(2)$ conductance and $\mathrm{CO}(2)$ assimilation in the leaves of transgenic rice plants. Plant Cell Physiol 45(5): 521-529. 
38. Flexas J, Ribas Carbó M, Hanson DT, Bota J, Otto B, et al. (2006) Tobacco aquaporin $\mathrm{NtAQP1}$ is involved in mesophyll conductance to $\mathrm{CO}_{2}$ in vivo. Plant J 48(3): 427-439.
39. Uehlein N, Sperling H, Heckwolf M, Kaldenhoff R (2012) The Arabidopsis aquaporin PIP1;2 rules cellular $\mathrm{CO}_{2}$ uptake. Plant Cell Environ 35(6): $1077-1083$.

For possible submissions Click below: 